\title{
Optical Response of Coated Iron Oxide(s) Nanoparticles Towards Biomedical Applications
}

\author{
Pradeep Bhatia*, Suram Singh Verma, Murari Mohan Sinha \\ Department of Physics, Sant Longowal Institute of Engineering and Technology, Sangrur, India \\ Email address: \\ pardeepbhatiahp@gmail.com (P. Bhatia), ssvermaus2001@yahoo.com (S. S. Verma),mm_sinha@rediffmail.com (M. M. Sinha) \\ ${ }^{*}$ Corresponding author
}

\section{To cite this article:}

Pradeep Bhatia, Suram Singh Verma, Murari Mohan Sinha. Optical Response of Coated Iron Oxide(s) Nanoparticles Towards Biomedical Applications. American Journal of Optics and Photonics. Vol. 5, No. 6, 2017, pp. 67-72. doi: 10.11648/j.ajop.20170506.12

Received: October 21, 2017; Accepted: November 17, 2017; Published: December 20, 2017

\begin{abstract}
We studied the optical properties of coated iron and its oxide (s) nanoparticles as core and silver/gold as shell materials because of their fascinating properties in tissue engineering, cancer therapy, and information storage. The maximum absorption peaks for $\mathrm{Fe}, \mathrm{FeO}, \mathrm{Fe}_{2} \mathrm{O}_{3}$ and $\mathrm{Fe}_{3} \mathrm{O}_{4}$ are found at $421 \mathrm{~nm}, 1500 \mathrm{~nm} .1169 \mathrm{~nm}$ and $1100 \mathrm{~nm}$ with $\mathrm{Ag}$ coating, and 530 $\mathrm{nm}, 1507 \mathrm{~nm}, 1115 \mathrm{~nm}$ and $1200 \mathrm{~nm}$ with Au coating. Furthermore, the larger absorption efficiency has been found at $16 \mathrm{~nm}$ $\mathrm{Ag} / \mathrm{Au}$ shell thickness of all considered core-shell nanostructures and especially absorption efficiency gradually increases for entire considered $\mathrm{Au}$ shell thickness. The largest LSPR is found for $\mathrm{Fe}_{2} \mathrm{O}_{3}$-core with $\mathrm{Ag}$ and $\mathrm{Au}$-shell. It is found that the absorption LSPR spectra which are almost fixed for coated iron and varied for coated iron oxides, shows the tunability in the visible and NIR region respectively with increasing shell thickness. The LSPR peaks in visible and NIR region of electromagnetic spectrum opens the door to photonic-magnetic nanodevices, and therapeutic applications.
\end{abstract}

Keywords: Core-Shell, Absorption Spectra, Noble Metals, NPs, MNPs, LSPR

\section{Introduction}

Nanotechnology and nanoscience is a field of present research which deals with design, synthesis and study the materials, structures, particle on the scale of nanometers. The particles which have two or more dimensions in size range 1$100 \mathrm{~nm}$ are defined as nanoparticles. Nanoparticles (NPs) have unique properties as compared to its bulk counter because of their high surface to volume ratio. These NPs have a wide range of application in different zones such as optics, material sciences, biomedical, and mechanics $[1,2]$. Nanoparticles can be used in pharmaceuticals purpose and drug delivery.

Gold and silver NPs have been used in different pharmacy applications, biosensor materials, superconducting materials, composite fibers and electronic components due to unique properties such as high disparity, inert nature, noncytotoxicity, and biocompatibility. Further, it can also be used in medicine, drug delivery and biological images [3, 4]. Gold NPs are widely used in nanotechnology and biomedical field because of their high electron conductivity and proven the safest and less toxic agents for drug delivery [5]. On the other hand, Silver NPs have distinctive properties, such as good conductivity, chemical stability, catalytic activity, and antimicrobial activity. These NPs are synthesized by many routes (physical and chemical methods) [6, 7].

Whereas magnetic NPs are used in data storage, permanent magnets, catalyst, drug targeting, therapy including cell sorting, hyperthermia and magnetic resonance imaging (MRI) $[8,9]$ due to unique properties such as to generate the magnetic field, provide the magnetic control over surface plasmon and high flux density. Currently, MNPs are also used in essential bioapplications and detection of various biological entities such as a cell, protein, nucleic acids, enzyme, and virus. MNPs get oxidised easily in the air due to the environmental situation. To this end, magnetic NPs have more need to explore in depth. Several allotropes of iron oxides viz. $\mathrm{FeO}, \alpha / \gamma / \beta / \varepsilon-\mathrm{Fe}_{2} \mathrm{O}_{3}, \mathrm{Fe}_{2} \mathrm{O}_{4}$, and $\mathrm{Fe}_{3} \mathrm{O}_{4}$ have been investigated [10] among which $\mathrm{Fe}_{2} \mathrm{O}_{3}$ and $\mathrm{Fe}_{3} \mathrm{O}_{4}$ are promising candidates due to biocompatibility. Also, $\alpha-\mathrm{Fe}_{2} \mathrm{O}_{3}$ 
is most stable iron oxides with n-type semiconducting properties and has been extensively used in bioapplications including sensors catalyst due to its low cost and high resistance to corrosion [11]. Now, the iron oxides NPs became the strong candidates and open the new door in biomedical application [12].

The latest trend in the research is to build the metamaterials by combining other materials with the leading materials which increase their functionalities and opens a new application on a broad scale. On this basis, magnetic NPs can be combined with the noble metal NPs and fabricated the new functionalize nanostructures with abundant properties known as magnetoplasmonics. For the plasmonic study, optical properties are determined by conduction electrons of non-magnetic noble metal such as $\mathrm{Au}, \mathrm{Ag}$ and $\mathrm{Cu}$ and also exhibit small magneto-optical (MO) effect. Furthermore, plasma oscillations in magnetic materials exhibit stronger damping than the non-magnetic materials. To overcome this excess damping, a common strategy is to make hybrid structures consisting of noble metals and magnetic materials [13, 14]. Therefore, MNPs can't be used alone for the magnetoplasmonics system, but they can be embedded with the noble metals NPs in the form of core-shell or multi-layered structure to increase the MO effects.

On reviewing the literature, it has been found that the selection of magnetic nanoparticles with loss of dispersibility and oxidation is a major challenge in biomedical. In this regard, we have studied the optical properties of core-shell of magneto-plasmonic. $\mathrm{Xu}$ et al. [15] studied the plasmonic (absorption) properties of $\mathrm{Fe}_{3} \mathrm{O}_{4} / \mathrm{Au}$ and $\mathrm{Fe}_{3} \mathrm{O}_{4} / \mathrm{Au} / \mathrm{Ag}$ nanoparticles. Thus, we have studied the optical properties of iron $(\mathrm{Fe})$ and its oxides $\left(\mathrm{FeO} / \mathrm{Fe}_{2} \mathrm{O}_{3} / \mathrm{Fe}_{3} \mathrm{O}_{4}\right)$ by calculating the absorption efficiencies. Further, the goal of this research is to see the effect of $\mathrm{Ag} / \mathrm{Au}$ shell thickness on the considered magnetic NPs and also explore the optical tunability of coreshell nanostructures in biomedical and therapeutic applications.

\section{Computational Details}

Optical properties of core-shell spherical NPs are calculated by extended Mie theory implemented in computer [16] program available as Mielab. Mie theory is one of the fundamental theories used in predicting optical properties of spherical particles. Recently, Jain et al. [17] have predicted the optical properties of homogeneous gold nanospheres and silica-nanoshell on the basis of Mie theory. In Mie theory optical efficiencies of core-shell nanoparticles obtained from below equations:

$$
\begin{aligned}
& Q_{e x t}=\frac{2}{x^{2}} \sum_{n=1}^{\infty}(2 n+1) \operatorname{Re}\left[a_{n}+b_{n}\right] \\
& Q_{\text {sca }}=\frac{2}{x^{2}} \sum_{n=1}^{\infty}(2 n+1)\left[a_{n}^{2}+b_{n}^{2}\right]
\end{aligned}
$$

$$
\begin{aligned}
& Q_{\mathrm{abs}}=Q_{\mathrm{ext}}-\mathrm{Q}_{\mathrm{sca}} \\
& \mathrm{a}_{\mathrm{n}}=\frac{\mathrm{m} \varphi_{\mathrm{n}}(\mathrm{mx}) \varphi_{\mathrm{n}}^{\prime}(\mathrm{x})-\varphi_{\mathrm{n}}(\mathrm{x}) \mathrm{y}_{\mathrm{n}}^{\prime}(\mathrm{mx})}{\mathrm{m} \varphi_{\mathrm{n}}(\mathrm{mx}) \varepsilon_{\mathrm{n}}^{\prime}(\mathrm{x})-\mathrm{m} \varepsilon_{\mathrm{n}}(\mathrm{x}) \varphi_{\mathrm{n}}^{\prime}(\mathrm{mx})} \\
& \mathrm{b}_{\mathrm{n}}=\frac{\varphi_{\mathrm{n}}(\mathrm{mx}) \varphi_{\mathrm{n}}^{\prime}(\mathrm{x})-\mathrm{m} \varphi_{\mathrm{n}}(\mathrm{x}) \varphi_{\mathrm{n}}^{\prime}(\mathrm{mx})}{\varphi_{\mathrm{n}}(\mathrm{mx}) \varepsilon_{\mathrm{n}}^{\prime}(\mathrm{x})-\mathrm{m} \varepsilon_{\mathrm{n}}(\mathrm{x}) \varphi_{\mathrm{n}}^{\prime}(\mathrm{mx})}
\end{aligned}
$$

where $m$ is the ratio of refractive index of the sphere $n$ to that of the surrounding medium $n_{m}, x$ is the size parameter given as $2 \pi n_{m} R / \lambda, \varphi_{n}$ and $\varepsilon_{n}$ are the Riccati-Bessel functions, and the prime represents first differentiation with respect to the argument in parentheses. Numerical calculations of the Mie series are performed at discrete points in the wavelength range from 200 to $1200 \mathrm{~nm}$.

Input parameters are the thickness of each layer, real (n) and imaginary $(\mathrm{k})$ parts of the complex refractive index corresponding to energy in electron volt $(\mathrm{eV})$ and the last parameter is the refractive index of the surrounding medium. Values of dielectric constant for $\mathrm{Ag} / \mathrm{Au}$, iron and its oxides, as a function of wavelength, were taken from John and Christy, and M. R. Querry [18-20]. The refractive index of the surrounding medium was considered $1.330+0 \mathrm{i}$ (water) at all wavelengths. The size (thickness) of the core-shell nanospheres, defined by the total radius $\left(\mathrm{R}_{\text {total }}\right)$ for a considered structure, is the sum of the radii of the magnetic core $\left(\mathrm{R}_{\text {core }}\right)$ and the noble metal shell $\left(\mathrm{R}_{\text {shell }}\right)$. Mie theory takes less time, is cost effective and gives the same results as compared to other methods. However, there are other methods for complex geometries such as discrete dipole approximation (DDA) and finite difference time domain (FDTD) [21] which are frequency and time domain numerical method.

\section{Results and Discussion}

We simulated the optical properties for the considered nanospheres of iron, its oxides as core and coated with $\mathrm{Ag}$ and $\mathrm{Au}$ as shell materials. Here, we considered the $20 \mathrm{~nm}$ size of the iron and its oxides in order to uphold their superparamagnetic properties as required in the biomedical field. The shell thickness of $\mathrm{Ag}$ and $\mathrm{Au}$ are varied as $1 \mathrm{~nm}, 2$ $\mathrm{nm}, 4 \mathrm{~nm}, 8 \mathrm{~nm}$ and $16 \mathrm{~nm}$ represented in figure 1 with representations of $\mathrm{A}, \mathrm{B}, \mathrm{C}, \mathrm{D}$, and $\mathrm{E}$ respectively. The considered core materials are represented as: 1(Fe), 2(FeO), $3\left(\mathrm{Fe}_{2} \mathrm{O}_{3}\right)$ and $4\left(\mathrm{Fe}_{3} \mathrm{O}_{4}\right)$. Absorption spectra of $\mathrm{Fe}$ core with varying shell thickness of $\mathrm{Ag}$ and $\mathrm{Au}$ are as shown in figure 1(a,b). As shell thickness increases, the LSPR shifts towards the higher wavelength and maximum peaks are found at wavelengths $421 \mathrm{~nm}$ and $530 \mathrm{~nm}$ of $16 \mathrm{~nm}$ shell thickness of $\mathrm{Ag}$ and $\mathrm{Au}$ respectively. With the increasing shell thickness, absorption LSPR is found in the visible region of the electromagnetic (EM) spectrum. Thus, the obtaining spectra have no LSPR peak tunability along EM spectrum. 

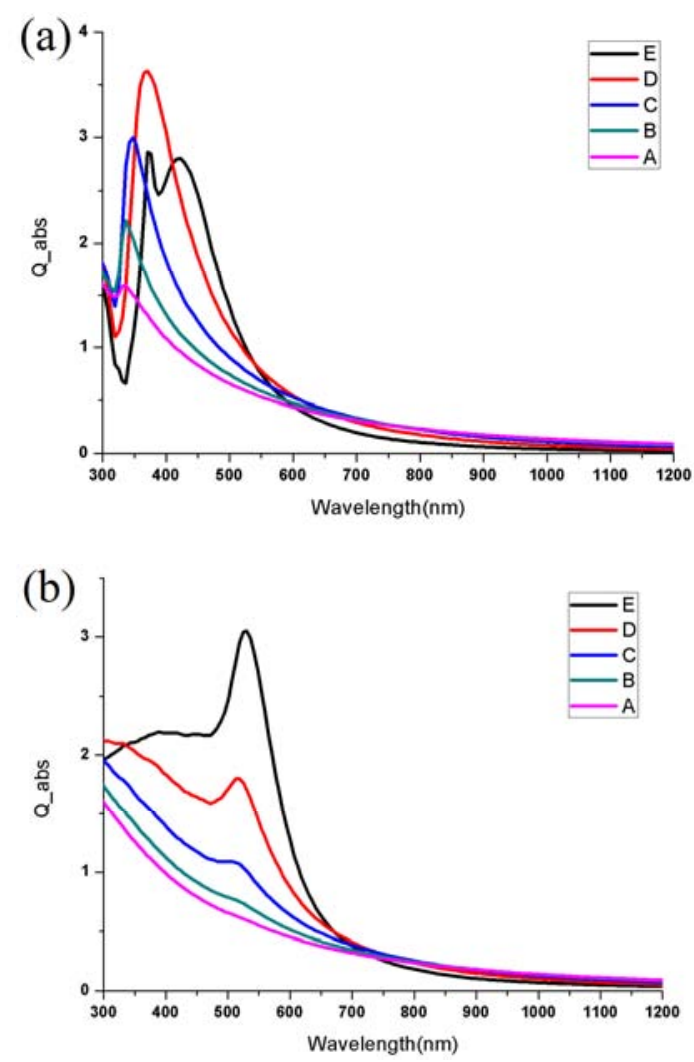

Figure 1. Simulated absorption spectra of core-Fe with various shell- Ag/Au thickness.
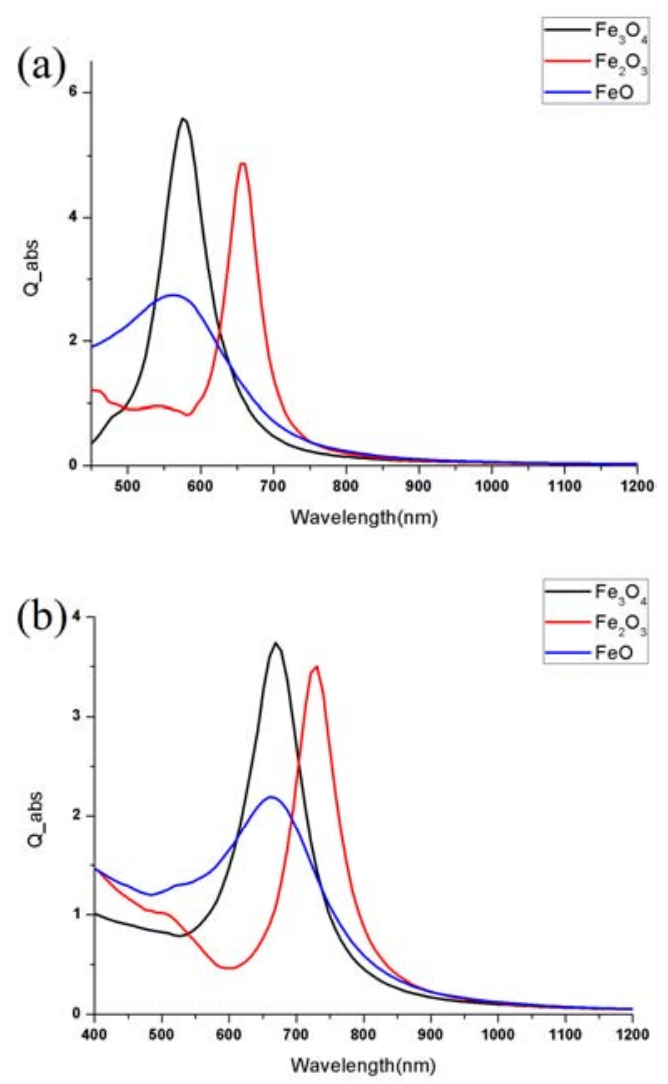

Figure 2. Simulated LSPR peaks of core-shell with $8 \mathrm{~nm} \mathrm{Ag} / \mathrm{Au}$ shell thickness.
Figure 2(a, b) shows the LSPR peaks of $\mathrm{FeO}, \mathrm{Fe}_{2} \mathrm{O}_{3}$ and $\mathrm{Fe}_{3} \mathrm{O}_{4}$ for $8 \mathrm{~nm} \mathrm{Ag} / \mathrm{Au}$ shell thickness. $\mathrm{A}$ decent in absorption peak of core- $\mathrm{Fe}_{2} \mathrm{O}_{3}$ is found for as compared to another considered core materials $\left(\mathrm{FeO}\right.$ and $\left.\mathrm{Fe}_{3} \mathrm{O}_{4}\right)$. In addition, $\mathrm{Au}$ coating shows broad spectra and higher absorption efficiency on $\mathrm{Ag}$ coating. Figure 3(a,b) shows the LSPR shifting of iron and its oxides with varying the shell thickness from $1 \mathrm{~nm}$ to $16 \mathrm{~nm}$. On increasing the shell thickness for iron oxides, there are decreasing in the LSPR absorption peaks. Hence, LSPR peaks shifts from NIR to the visible region of EM spectrum. The maximum LSPR is found at 1500,1169 and 1100 with $1 \mathrm{~nm}$ of $\mathrm{Ag}$ shell and also, the maximum peaks are 1507, 1115, 1200 for $\mathrm{Au}$ of $1 \mathrm{~nm}$ shell thickness. Therefore, the nanostructures represent the increasing order of LSPR as $\mathrm{Fe}<\mathrm{FeO} \leq \mathrm{Fe}_{3} \mathrm{O}_{4}<\mathrm{Fe}_{2} \mathrm{O}_{3}$ over the entire range of wavelength.
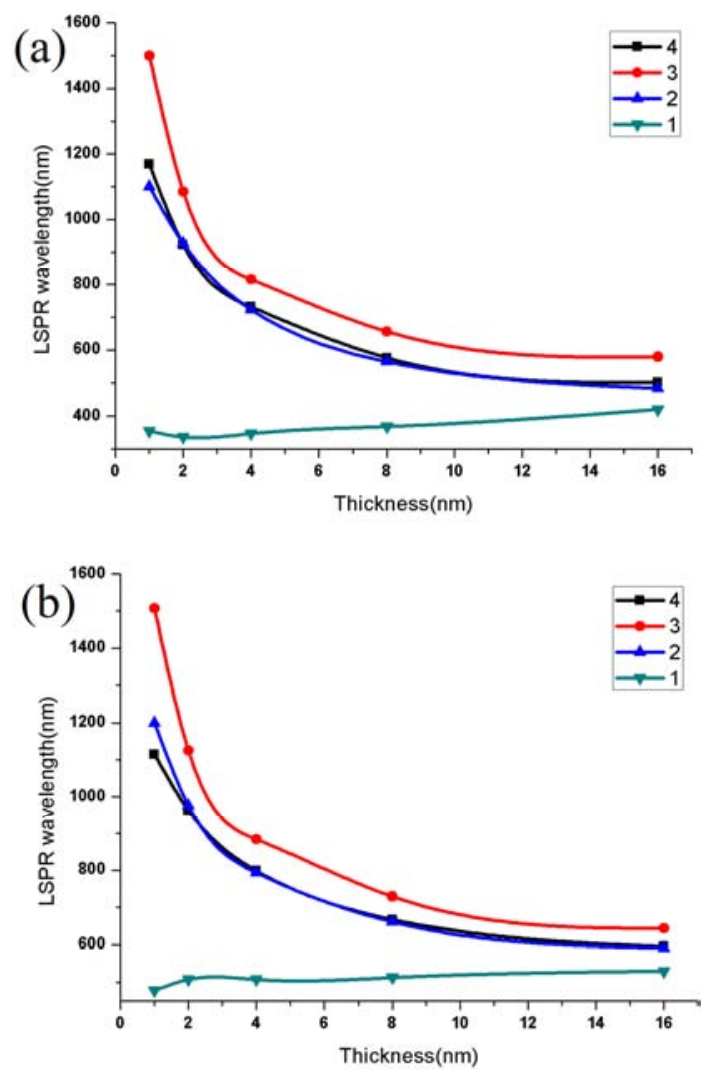

Figure 3. LSPR shifting of $\mathrm{Fe}, \mathrm{FeO}, \mathrm{Fe}_{2} \mathrm{O}_{3}$, and $\mathrm{Fe}_{3} \mathrm{O}_{4}$ as a function of shell thickness. (a) silver shell and (b) gold shell.

Figure $4(a, b)$ shows the absorption efficiencies as a function of shell thickness for considered core-shell nanospheres. The absorption efficiency is continuous increases from $1 \mathrm{~nm}$ to $8 \mathrm{~nm}$ of Ag shell thickness and further efficiency decreases for $16 \mathrm{~nm}$ shell thickness for the core of $\mathrm{Fe}$ and $\mathrm{Fe}_{3} \mathrm{O}_{4}$. As the $\mathrm{Ag}$ shell thickness increases, the absorption efficiency of $\mathrm{FeO}$ and $\mathrm{Fe}_{2} \mathrm{O}_{3}$ continuously increases as shown in figure 4(a) with blue and red lines. Figure 4(b) also shows the absorption efficiencies of Au shell thickness. With increasing in Au shell thickness, there is a sharp increase in efficiency from $1 \mathrm{~nm}$ to $8 \mathrm{~nm}$ shell of $\mathrm{Au}$ for $\mathrm{Fe}_{2} \mathrm{O}_{3}$ and $\mathrm{Fe}_{3} \mathrm{O}_{4}$ cores and further, there is a small 
increase in absorption efficiency. Continuous increments in absorption efficiency have been seen for $\mathrm{Fe}$ and $\mathrm{FeO}$ cores. Furthermore, at $16 \mathrm{~nm}$ shell thickness, the absorption efficiency is decreasing for $\mathrm{Fe}$ and $\mathrm{Fe}_{3} \mathrm{O}_{4}$ cores on $\mathrm{Ag}$ coating but no decrease in absorption efficiency have been seen in $\mathrm{Au}$ coating. Hence, absorption efficiency increases of $\mathrm{Au}$ shell thickness.
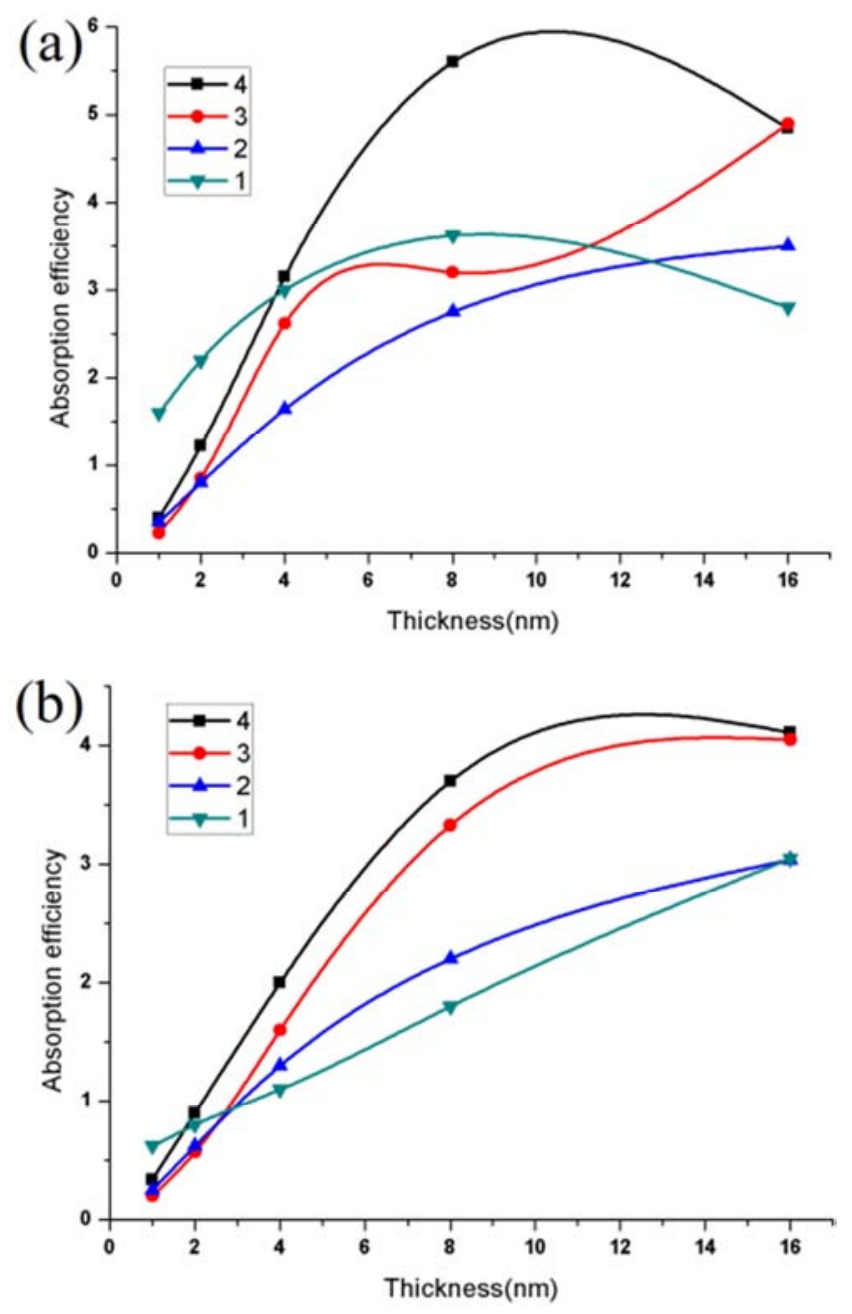

Figure 4. Absorption efficiency as a function of shell thickness.

In addition, we calculated the FWHM as a function of shell thickness of spherical shape core-shell nanostructures. Since FWHM is particularly required for plasmonic solar cells and bio-sensing applications. The effect of thickness on optical properties is shown in figure 5 and larger value of FWHM is found for oxides. On both Ag and Au coating, the FWHM is found to be larger of $1 \mathrm{~nm}$ shell thickness for oxides and is smaller for iron cores as shown in figure 5(a, b). As the shell thickness increases, the value of FWHM increases for iron cores and decreases for its oxides. Large FWHM is found for $\mathrm{Fe}_{2} \mathrm{O}_{3}$ as compared to other considered oxides. This FWHM is contributed by the imaginary part of the dielectric function.
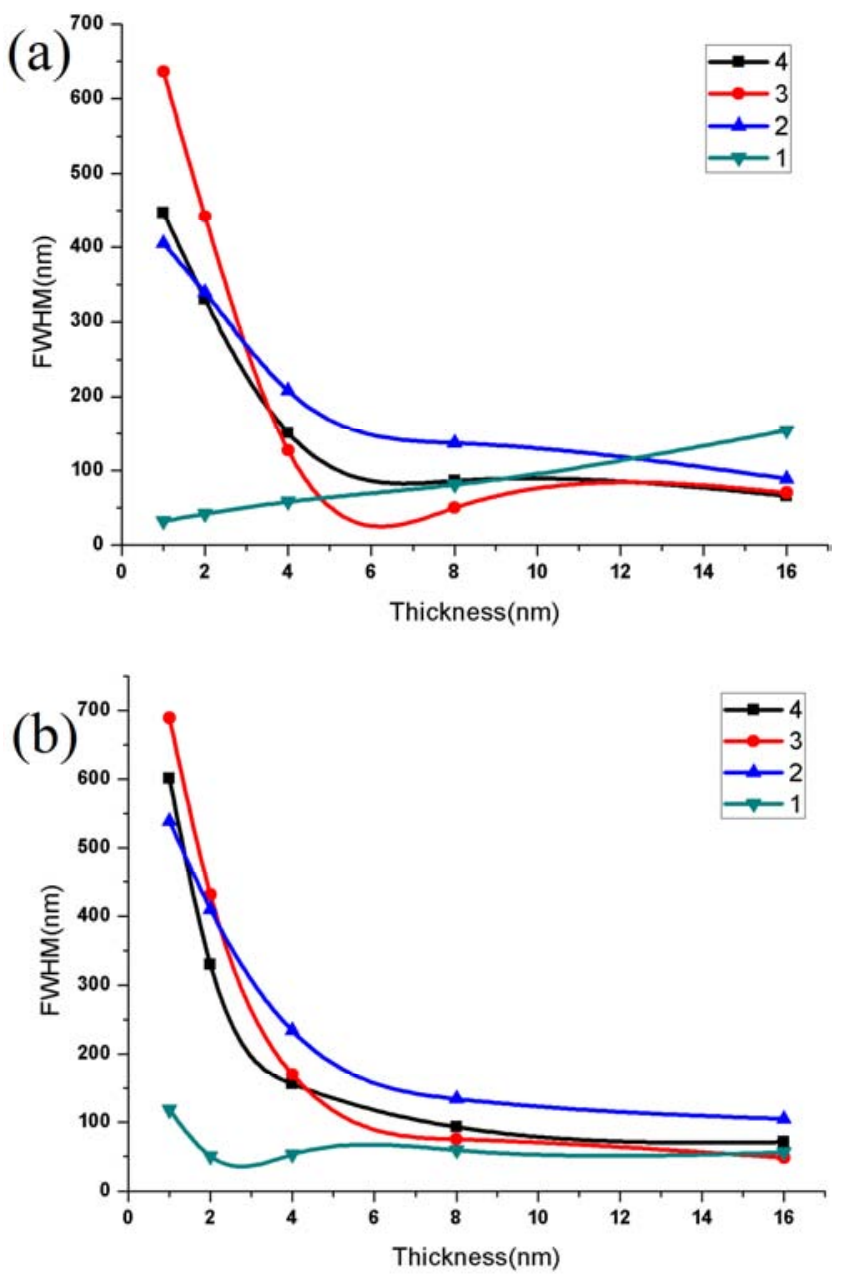

Figure 5. Evolution of FWHM of LSPR as a function of shell thickness.

Further, we calculated the relative contribution of absorption in the extinction is defined as the ratio of absorption to the extinction efficiency at each LSPR and given by $\eta=\left.\frac{Q_{a b s}}{Q_{e x t}}\right|_{L S P R}$. Figure 6 shows the thickness dependent absorption yield for different considered core-shell nanostructures. In comparison to other considered cores of iron and its oxides, Fe@Ag and FeO@Au shows the large absorption yield as shown in figure $6(\mathrm{a}, \mathrm{b})$. Absorption yield is decreases from $4 \mathrm{~nm}$ to $16 \mathrm{~nm}$ shell thickness of $\mathrm{Fe}$ and $\mathrm{Fe}_{2} \mathrm{O}_{3}$ cores and increases from $2 \mathrm{~nm}$ to $16 \mathrm{~nm}$ shell thickness of $\mathrm{Fe}_{3} \mathrm{O}_{4}$ core with $\mathrm{Ag}$ shell of both. For $\mathrm{FeO} @ \mathrm{Ag}$ core-shell, absorption is large at $2 \mathrm{~nm}$ thickness and decreases up to $8 \mathrm{~nm}$ shell thickness and then further increases for $16 \mathrm{~nm}$ shell thickness as clearly shown in figure 6(a). On the other hand, in figure 6(b) of Au coating, there is no decent trend of absorption yield with respect to shell thickness. Hence, absorption yield is continuously increases of $\mathrm{Fe}_{3} \mathrm{O}_{4} @ \mathrm{Ag}$ and decreases of $\mathrm{Fe}_{3} \mathrm{O}_{4} @ \mathrm{Au}$ with 2 to 16 nm shell thickness respectively. 

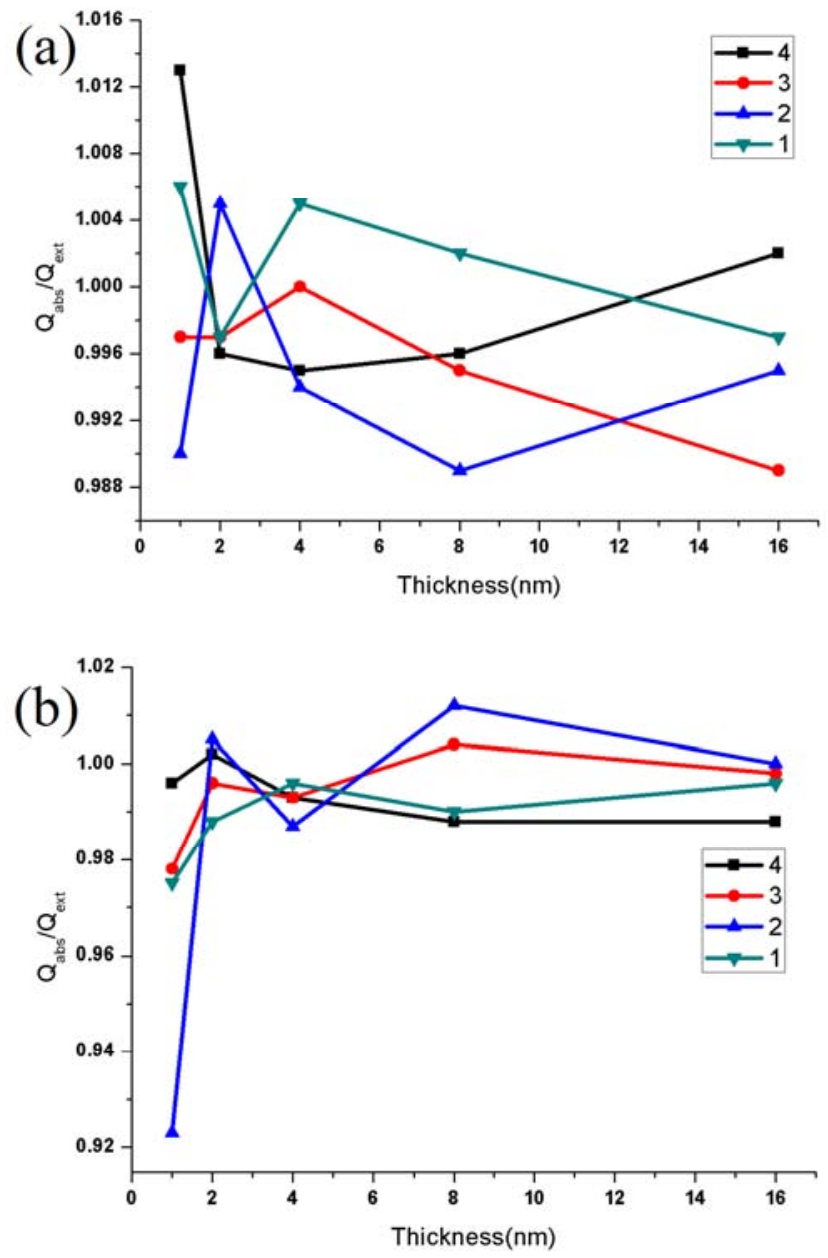

Figure 6. Absorption yield $\left(Q_{a b s} / Q_{e x t}\right)$ as a function of shell thickness.

The resulting spectra are found in visible and NIR region of EM spectrum. Therefore, larger LSPR and increasing order of absorption efficiency with a shell thickness of $\mathrm{Fe}_{2} \mathrm{O}_{3}$ as compared to other considered core-shell nanostructures makes the good candidate for potential application in cancer therapy and field of biomedical.

\section{Conclusions}

It is concluded that by changing the shell thickness, the optical properties of the core-shell nanostructure can be tuned over the EM spectrum. With the increase in shell thickness, the absorption LSPR peaks are shifted towards lower wavelength for iron cores and are shifted to lower wavelength for iron-oxides cores. The largest LSPR is found for $\mathrm{Fe}_{2} \mathrm{O}_{3}$-core with $\mathrm{Ag}$ and $\mathrm{Au}$-shell. The resulting spectra of iron and its oxides have been found in the visible region and NIR region respectively. Furthermore, the larger absorption efficiency has been found at $16 \mathrm{~nm}$ $\mathrm{Ag} / \mathrm{Au}$ shell thickness of all considered core-shell nanostructures and especially absorption efficiency gradually increases for entire considered $\mathrm{Au}$ shell thickness. In addition, a large value of FWHM may be useful for plasmonics solar cell and minimum value useful in bio-sensing applications. Therefore, depending upon the absorption efficiencies, absorption yield, and LSPR wavelength, the $\mathrm{Fe}_{2} \mathrm{O}_{3} @ \mathrm{Ag} / \mathrm{Ag}$ core-shell nanostructures may be useful in the plasmonic based application on the desired range on EM spectrum.

\section{Acknowledgements}

The author, Pradeep Bhatia, would like to thank the team of Ovidio Pena-Rodriguez for Mielab software. I am also thankful to S. L. I. E. T. for financial support in the form of institute fellowship towards my Ph.D.

\section{References}

[1] Ventra M. et al., "Introduction to nanoscale science and technology”, Springer Science \& Business Media, 2006.

[2] Alanazi F. K. et al., "Biopharmaceutical applications of nano gold”, Saudi Pharmaceutical Journal, Vol. 18, pp. 179-193, 2010 .

[3] Huang X. et al., "Gold nanorods: from synthesis and properties to biological and biomedical applications", Advanced Materials, Vol. 21, pp. 4880-4910, 2009.

[4] Alaqad K. \& Saleh T. A., "Gold and silver nanoparticles: synthesis methods, characterization routes and applications towards drugs", J. Environ. Anal. Toxicol, Vol. 6, pp. 21612165,2016

[5] Tedesco S. et al., "Oxidative stress and toxicity of gold nanoparticles in Mytilus edulis", Aquatic Toxicology, Vol. 100, pp. 178-186, 2010.

[6] Mafune F. et al., "Structure and stability of silver nanoparticles in aqueous solution produced by laser ablation", The Journal of Physical Chemistry B, Vol. 104, pp. 8333$8337,2000$.

[7] Iravani S. et al., "Synthesis of silver nanoparticles: chemical, physical and biological methods", Research in Pharmaceutical sciences, Vol. 9, pp. 385-406, 2014.

[8] Khan K. et al., "Synthesis and application of magnetic nanoparticles", Nanomagnetism, pp. 135-159, 2014.

[9] Shinkai M., "Functional magnetic particles for medical application", Journal Of Bioscience and Bioengineering, Vol. 94, pp. 606-613, 2002.

[10] Murad E. \& John C., "Mossbauer spectroscopy of environmental materials and their industrial utilization", Springer Science \& Business Media, 2011.

[11] Chen J. et al., " $\alpha-\mathrm{Fe}_{2} \mathrm{O}_{3}$ nanotubes in gas sensor and lithiumion battery applications", Advanced Materials, Vol. 17, pp. 582-586, 2005.

[12] Corot C. et al. "Recent advances in iron oxide nano crystal technology for medical imaging", Advanced Drug Delivery Reviews, Vol. 58, pp. 1471-1504, 2006.

[13] Brullot W. et al., "Magnetic-plasmonic nanoparticles for the life sciences: calculated optical properties of hybrid structures", Nanomedicine: Nanotechnology, Biology and Medicine, Vol. 8, pp. 559-568, 2012. 
[14] Cortie M. B. \& McDonagh A. M., "Synthesis and optical properties of hybrid and alloy plasmonic nanoparticles", Chemical Reviews, Vol. 111, pp. 3713-3735, 2011.

[15] Xu Z. et al., "Magnetic core/shell $\mathrm{Fe}_{3} \mathrm{O}_{4} / \mathrm{Au}$ and $\mathrm{Fe}_{3} \mathrm{O}_{4} / \mathrm{Au} / \mathrm{Ag}$ nanoparticles with tunable plasmonic properties", Journal of the American Chemical Society, Vol. 129, pp. 8698-8699, 2007.

[16] Pena-Rodriguez O. et al., "Mie Lab: A Software Tool to Perform Calculations on the Scattering of Electromagnetic Waves by Multilayered Spheres", International Journal of Spectroscopy, 2011.

[17] Jain P. K. et al., "Calculated absorption and scattering properties of gold nanoparticles of different size, shape, and composition: applications in biological imaging and biomedicine", Journal of Physical Chemistry B, Vol. 110, pp. 7238-7248, 2006.

[18] Johson P. B. \& Christy R. W., "Optical Constants of Noble Metals”, Physical Review B, Vol. 6, pp. 4370- 4379, 1972.

[19] Johson P. B. \& Christy R. W., "Optical Constants of Transition Metals”, Physical Review B, Vol. 9, pp. 5056-5070, 1974.

[20] Querry M. R. "Optical Constants”, Missouri University-Kanas City, 1985.

[21] Mishchenko M. I. et al., "Light scattering by non-spherical particles: theory, measurements, and applications", Academic press, 1999. 